\title{
Analysis of Signal Attenuation in Digital Terrestrial Television (DTTV) Broadcasting
}

\author{
B. I. Bakare, K. J. Biebuma, and Sunny Orike
}

\begin{abstract}
This paper presents the prediction of signal attenuation Digital Terrestrial Television (DTTV) in Port Harcourt, Rivers State, Nigeria A signal Tracker (WS6916), Micronix Global Positioning System (GSP) module alongside a drive test was used to carry out the research work at Star times office, Olu-Obasanjo Road. The Power Density change with the varying distance between the receiver and the transmitter (Nobe B). For a more concise measurement, readings were taken between April and August, 2019 (wet season) at different times of the day. The path loss exponent (n) of 4.7 reveals that OluObasanjo road is an urban area. As the location changed, the path loss exponent (n) increased to 15.4 , revealing the interference of tall buildings, and other forms of obstruction. The exponential shape of the graph shows a decaying signal along the distance axis with distance, expatiating that the inverse relationship between powers received $(\mathrm{dbm})$ and distance $(\mathbf{k m})$. Attenuation was observed to have increased while increasing the distance between the transmitter and receiver. The results obtained were analyzed using the log-distance empirical model to obtain both the parameters of Path loss exponent and the Mean Square Error (MSE).
\end{abstract}

Index Terms - Attenuation; Signal Tracker; Digitalization, Received Power; Transmitter; Broadcasting.

\section{INTRODUCTION}

Broadcasting of Television signals is a significant part of societal development. Over the years, people have longed for increase in entertainment, educating etc., over the television. This prompted the government in Nigeria to take measures in the fulfillment of this societal requirement, on October 31, 1959 , the then premier of the define Western Nigeria, late Chief Obafemi Awolowo established the first television station in Nigeria, known as the Western Nigerian Government Broadcasting Corporation (WNTV) [1].

The first Orthogonal Frequency Division Multiplexing (OFDM) based system for digital modulation of propagation in the early 90's was the Digital Video Broadcasting Television (DVB-T) [2]. A digital terrestrial TV is an improvement to analogue systems, whose robustness of modulation eliminates the limitations and shortcomings met by the DVB Consortium and standardized by the European Telecommunication Standard Institute (ETSI) [3] and [4]. The transmission of DTTV is usually on radio frequencies through the terrestrial space in a similar method of the transmission of analogue TV signal [5].

The NTA-Star TV Network, with the working name "Startimes" is a joint endeavor between the Nigerian Television Authority (NTA) and Beijing Star group. It is a key partnership between the biggest Television Network in
Africa (NTA), and China's most powerful radio TV endeavor. Startimes utilizes DVB-T2 as the national standard for Terrestrial Digital Television Broadcasts (DTTV), MPEG-4 $\mathrm{AVC} / 264$ as standard compression position for digital physical TV and Technology Neutral Mobile TV Standard for Portable TV [6].

The challenge of signal attenuation faced by subscribers of DTV can lead to a loss of potential customers, if nothing is done to either eliminate or reduce the attenuation of signals experienced by subscribers. This research investigates the factors that causes attenuation of TV signals in the broadcasting industry and takes measures to eliminate it. The research area of Olu-Obasanjo was considered and taken as a sub urban area, owing to the fact that different environments have their own level of signal attenuation arising from different kind of obstacles, interference, diffraction, reflection, refraction, vegetation effects etc., A signal tracker (WS9619) was used to measure the signal strength level at different location along Olu-Obasanjo road with Coordinates of $4048^{-} 52$ "N, $7012^{-} 6^{\prime \prime}$ E. in Port Harcourt, Nigeria as shown in figure 1 below

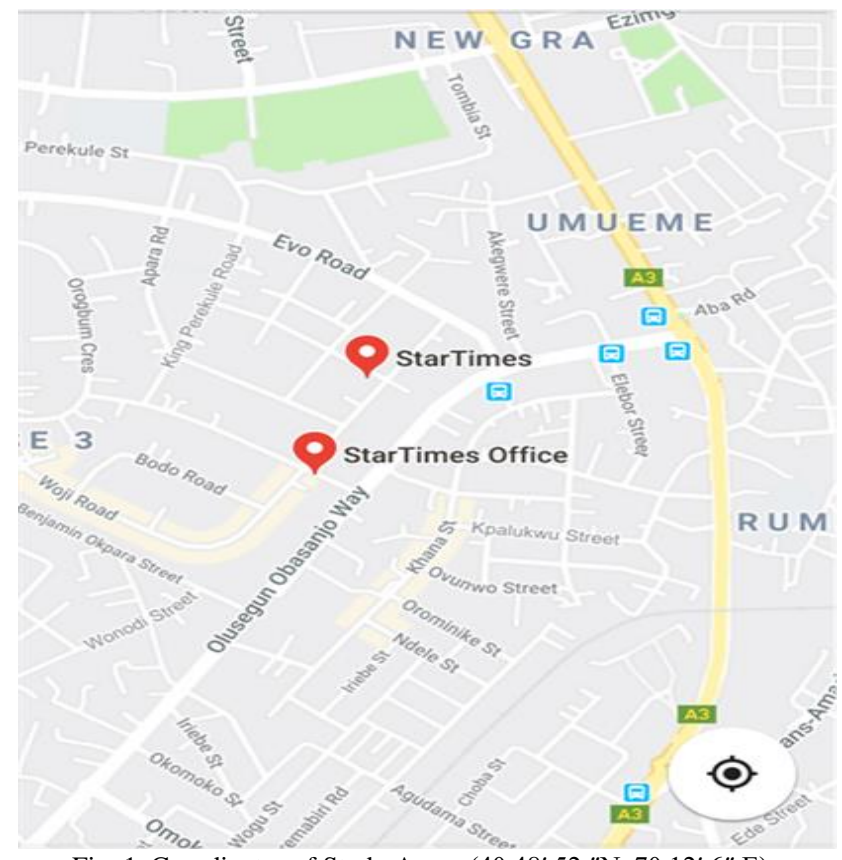

Fig. 1. Coordinates of Study Area $\left(4048^{\prime} 52\right.$ "N, 70 12' 6" E)

\section{Types Of PROPAGATION MODELS}

In the design of transmission system, the right propagation model or link budget should be taken into consideration.

K. J. Biebuma, Rivers State University, Nigeria Sunny Orike, Rivers State University, Nigeria. 
Empirical and Analytic models are usually considered because they are easier to interpret and understand, and also present a detailed description of the link budget parameters used in the design of the radio wave propagation transmitterreceiver systems. The propagation models are used in different environments, starting with the models that have few or no reflection, we then work our way up to more complex environment where electromagnetic waves are scattered, reflected and diffracted either by walls, buildings, terrains or any other objects etc.

The Frii's Free Space Formular [7] is given as;

$$
P_{R}=\frac{P_{T} G_{T} G_{R} \lambda^{2}}{L_{T} L_{R}(4 \pi d)^{2}}
$$

where

$\mathrm{PR}_{\mathrm{R}}=$ Received power,

$\mathrm{GR}=$ Receive antenna gain,

GT = Transmitter antenna gain,

$\mathrm{LR}=$ Receiver losses,

$\mathrm{LT}=$ Transmitter losses,

$\lambda=$ Signal wavelength,

$\mathrm{d}=$ Distance between transmitter and the receiver antenna.

\section{A. Free Space Propagation Model}

The Free Space Propagation model predicts the delay in the received power as a function of the separation distance between the transmitter and the receiver, when the channel is free of all obstacles that could cause reflections, diffraction and scattering to RF propagation. A Free space channel is an ideal propagation path where radio waves propagate in a direct and unobstructed manner (LOS). This can be understood by using the concept of an isotropic antenna coupled to a transmitter of power (Pt). An isotropic antenna is an antenna that radiates power uniformly in all directions [7]. The Effective Isotropic Radiated Power (EIRP) is given as the product of transmitted power $(\mathrm{Pt})$ and the Power Gain (Gt) of the transmitting antenna.

$$
\mathrm{EIRP}=\mathrm{PtGt}
$$

The Power Density, PD (i.e. Power Per Unit Area) for a spherical transmitting antenna in the direction to the receiving antenna is expressed as:

$$
\mathrm{P}_{\mathrm{D}}=\frac{E I R P}{4 \pi d^{2}}=\frac{P_{T} G_{T}}{4 \pi d^{2}}
$$

Where $\mathrm{d}$, is the distance between the transmitting antenna, $\mathrm{T}$ and Receiving antenna, $\mathrm{R}$ according to this model, the signal strength received by the receiver antenna $(R)$ decays at the rate of $20 \mathrm{~dB}$.ubmit your manuscript electronically for review.

\section{B. Plane Earth Propagation Model}

The plane earth model (Length) is used to predict received signal strength over plane earth surface. In a mobile radio channel, when radio waves propagates from transmitter over ground, some of the transmitted power will be reflected. This effect is due to the presence of the ground. Therefore, the model assures that the signal reaches the receiver through two paths. The most important parameters in this model include the length of the path and the antenna heights, the operating frequency and the reflection of the earth. The Total Received Power (Етот) at the receiving end is the vector sum of power due to LOS path between the transmitter and the receiver ELos and the power obtained by the reflection between the transmitter and the receiver separated by the same distance, ER.

$$
/ E_{\text {TOT }} /=/ E_{L O S} /+/ E_{R} /
$$

The plane earth propagation model [ $\left.\mathrm{L}_{\text {earth }}(\mathrm{dB})\right]$ with antenna gain can be given as:

$$
\mathrm{L}_{\text {earth }}(\mathrm{dB})=40 \log _{10}(\mathrm{~d} \text { in meters })-\left(10 \log _{10}\right)
$$

$$
\left.\left(G_{t}\right)+10 \log 10(\mathrm{Gr})+2 \log _{10} \mathrm{~h}_{\mathrm{t}}+20 \log 10 \mathrm{~h}_{\mathrm{r}}\right]
$$

\section{Long - Distance Path Loss Model}

This model indicates that average signal strength power decreases logarithmically will distance whether for indoor or outdoor propagation (Rappaport, 2006). The average pathloss at any given location is expressed as a function of the path loss at a reference distance, do and pathloss exponent, $\mathrm{n}$.

$$
\begin{aligned}
& L(d) \alpha\left(\frac{d}{d_{o}}\right)^{n} \\
& L(d B)=L\left(d_{o}\right)+10 n \log \left(\frac{d}{d_{o}}\right)
\end{aligned}
$$

Where do is the reference distance taken in the near field of the transmitting antenna, $\mathrm{n}$ indicates the rate at which path loss increases with distance. The value of $n$ depends on the propagating environment. In a free space, $\mathrm{n}$ is taken to be 2 , and when obstructions are, $n$ will have a larger value. In DTT systems, transmitted signal experience attenuation due to blockage from objects in the propagating channel, giving rise to random variation of the received signal at a particular location. The model mentioned above does not consider the effects of the surrounding cluster environment.

\section{Log-Normal Shadowing Model}

This model describes the random shadowing effect that occur over a large number of measurement locations with the equal separation between the transmitter and the receiver.

Accounting for different attenuation at various locations, the allowable path loss yields.

$$
\begin{aligned}
& L(d)=L(d o)+10 n_{1} \log _{10}\left(\frac{d_{o}}{d_{1}}\right)+10 n 2 \log 10\left(\frac{d_{o}}{d_{2}}\right) \\
& +\ldots+10 n-r \log _{10}\left(\frac{d_{r 1}}{d o}\right)+X \sigma_{n o}+\ldots X \sigma_{n-1}
\end{aligned}
$$

The difficulties encountered in modeling different characteristics of various bases for statistical model analysis of the field measurement, show that at any separation distance 
between Nobe B and the UE, the observed attenuation, L(d) is random and log normally distributed about the distance dependent.

This is given as:

$L(d B)=L(d o)+10 n \log \left(\frac{d}{d o}\right) X \sigma$

Where $X \sigma$ is a zero mean Gaussian distributed random variation (in $\mathrm{dB}$ ) with standard deviation $(\sigma)$ in $\mathrm{dB}$. The values of pathloss exponent $n$, and the reference pathloss (do) are calculated using linear regression algorithm as given below as:

$$
n=\frac{k \sum_{i}^{k}=1\left(X_{i} Y_{i}\right)-\sum_{i}^{n}=1\left(X_{i}\right) \sum_{i}^{n}=1\left(Y_{i}\right)}{k \sum_{i}^{k}={ }_{1}\left(X^{2}\right)-\left(\sum_{i}^{k}={ }_{1} X\right)}
$$

$$
\frac{L=\sum_{i}^{k}={ }_{1} Y_{i}-n \sum_{i}^{k}=2 X_{i}}{n}
$$

\section{E. Hata Propagation Model}

This represents a set of equation obtained on measurements and extrapolations taken from curves derived by Okumura. When using Okumura's model, an engineer finds a value for each term from the plots based on the parameters, such as the frequency, the height of the antenna, and the terrain type for the communication link. Unfortunately, this method does lend itself well for computer analysis. For this reason Hata established parametric equations that fit the curves reported by Okumura. Using Hata model, an engineering need only to plug parameters into the empirically derived. Thus, Hata would simplifies the path prediction and formulates the results as obtained in the Okumura model. This model function to approximate Okumura's model for distances that are greater than $1 \mathrm{~km}$ and is also appropriate for the frequency range from $150 \mathrm{MHz}$ to $1500 \mathrm{MHz}$. It gives a standard formular for the pathloss prediction in an urban environment. This standard formular for the median pathloss in an urban area using the Hata's model is given as:

$$
\begin{aligned}
& M_{50}(\text { urban })[d B)=6.955+26.16 \log f-1 \\
& 3.82 \log (\text { hre })+44.9-6.55 \text { Loghte }) \text { Logd }
\end{aligned}
$$

Where:

$\mathrm{F}_{\mathrm{c}}$ represents the frequency from $150 \mathrm{MHz}$ to $1500 \mathrm{MHz}$; $\mathrm{H}_{\mathrm{te}}$ give effective height of mobile station antenna $(\mathrm{km})$; $\mathrm{d}$ shows the transmitter- receiver separation distance $(\mathrm{km})$.

\section{F. COST 231 Model}

The cooperation for scientific and technical research is the full meaning of cost. It is applied in frequency range between $1500 \mathrm{MHz}$ to $2000 \mathrm{MHz}$, and also the height of the transmitter antenna (hre) with range between $1 \mathrm{~m}$ to $10 \mathrm{~m}$ and then the transmitter to receiver separation (d) ranging from $1 \mathrm{~km}$ to $20 \mathrm{~km}$. the propagation model considers the Hata model and thus gives a general expression for its median pathloss in an urban environment thus:

$$
\left[\begin{array}{l}
M_{50}(\text { urban })[d B)=46.3+33.9 \log F-13.82 \log \left(h_{t e}\right)- \\
9\left(h_{r e}\right)+\left(44.6 .55 \log \left(h_{t} e\right) \log (d)+c m\right.
\end{array}\right]
$$

In this case, $\mathrm{cm}$ here equals $3 \mathrm{~dB}$ for metropolitan areas and $0 \mathrm{~dB}$ for medium city or sub urban area.

The correction factor for urban environment is thus:

$$
\mathrm{C}\left(\mathrm{h}_{\mathrm{te}}\right)=3.2\left(\log 11.75 \mathrm{~h}_{\mathrm{te}}\right) 2-4.97 \mathrm{db}(12 \mathrm{~cm})
$$

Similarly, correction for sub urban areas is given as:

$$
\left.C\left(h_{t e}\right)=1.11 \log _{10}(f)-0.7\right) \text { the }\left(1.5 \log _{10}(f)-0.8\right.
$$

Where $h_{\text {te }}$ represents the antenna height of the receiver in metres

\section{MATERIALS AND METHOD}

In the analysis of signal attenuation in Digital Terrestrial Television (DTT), practical data from the survey were analyzed. Data were collected in a mobile field measurement unit, on which an antenna was mounted, serving as a means of transportation from one location to another (drive test). A signal tracker (WS6916) as shown in figure 2, a Global Positioning System (GPS) module was also used to measure and monitor measure distance and location co-ordinates. The StarTimes transmitting base station located inside the Nigerian Television Authority (NTA) premises at NTA, Mgbuogba on Latitude $4.8635^{\circ} \mathrm{N}$ and on Longitde $6.9618^{\circ} \mathrm{E}$, served as the reference base. The area considered for study, is StarTimes Office, Olu-Obasanjo Road. The analysis was carried out consecutively for five months (i.e. April to August). Measurement was made in the Dry and Wet seasons and in the Morning and Evening periods. To ensure accurate results, the equipment was tested, to ensure none was faulty. Several readings such as the Received Signal Level (RSCP), the distance from the transmitting antennas, the Mean Square Error (MSE), the Zero-Mean Goussian distributed random variable was computed and the values substituted into an empirical model, the path loss Exponent (n) were measured and recorded. A MATLAB Software was used to collate and analyze the results of the measurement from the field.

The transmitting equipment employed was a $1574 \mathrm{~K} 1$ model, with power operation of $52 \mathrm{~dB}$ turned to channel 107 on StarTimes, occupying the frequencies between 472$806 \mathrm{MHz}$ (UHF band), Radian system model TTSL8 UO-41100, Omnidirectional, with 8 slots, with a total gain of $10.89 \mathrm{~dB}$ and Modulation is 64QAM, the guard and interval is 1116 and the FEC range is $3 / 4$.

The Receiving equipment employed was an $8 \mathrm{~m}$ telescopic must, a log-periodic antenna with full UHF band for reception of channel 101. Signal Tracker (WS6916), a digital television receiver connected to a display with an aspect ratio of 16:9, a laptop for data collection. 


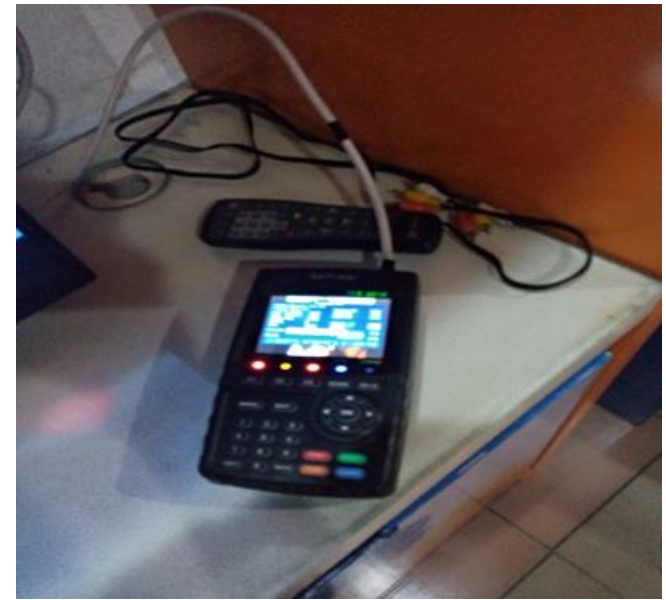

Fig. 2. Signal Tracker (WS6916).

The results of the measurements obtained are represented in the tables below.

Measurement and value for the month of April.

Research Area: StarTimes, Olu-Obasanjo.

Frequency of Transmission: 680MHz (UHF band).

Date: 17/4/2019.

\begin{tabular}{cccc}
\multicolumn{4}{c}{ TABLE I: READING AT STARTIMES, OLU-OBASANJO ROAD } \\
\hline Distance $(\mathrm{m})$ & $\begin{array}{c}\text { Power } \\
\text { Transmitted } \\
(\mathrm{dBm})\end{array}$ & $\begin{array}{c}\text { Power } \\
\text { Received } \\
(\mathrm{Bm})\end{array}$ & $\begin{array}{c}\text { Attenuation } \\
(\mathrm{dBm})\end{array}$ \\
\hline 0.520 & 52 & -62 & 114 \\
0.600 & 52 & -63 & 115 \\
0.720 & 52 & -68 & 120 \\
0.800 & 52 & -68 & 120 \\
0.870 & 52 & -72 & 124 \\
0.950 & 52 & -73 & 125 \\
1.050 & 52 & -75 & 127 \\
1.110 & 52 & -77 & 129 \\
1.250 & 52 & -83 & 135 \\
1.400 & 52 & -89 & 141 \\
\hline
\end{tabular}

Measurement and value for the Month of May.

Research Area: StartTimes Office, Olu-Obasanjo Road.

Frequency of Transmission: 680MHz (UHF).

Date: $10 / 5 / 2019$.

\begin{tabular}{cccc}
\multicolumn{4}{c}{ TABLE II: READING AT THE RESEARCH AREA } \\
\hline Distance $(\mathrm{m})$ & $\begin{array}{c}\text { Power } \\
\text { Transmitted } \\
(\mathrm{dBm})\end{array}$ & $\begin{array}{c}\text { Power } \\
\text { Received } \\
(\mathrm{dBm})\end{array}$ & $\begin{array}{c}\text { Attenuation } \\
(\mathrm{dBm})\end{array}$ \\
\hline 0.8700 & 52 & -70 & 122 \\
0.9300 & 52 & -72 & 124 \\
0.9500 & 52 & -78 & 130 \\
1.110 & 52 & -83 & 135 \\
1.230 & 52 & -87 & 139 \\
1.360 & 52 & -88 & 140 \\
1.580 & 52 & -90 & 142 \\
1.740 & 52 & -94 & 146 \\
1.950 & 52 & -95 & 147 \\
2.300 & 52 & -96 & 148 \\
\hline
\end{tabular}

Measurements and values for the Month of June.

Research Area: StarTimes Office, Olu-Obasanjo Road.

Frequency of Transmission: $680 \mathrm{MHz}$ (UHF band).

Date: 7/6/2019.
TABLE III: READING AT RESEARCH AREA

\begin{tabular}{cccc}
\hline $\begin{array}{c}\text { Distance } \\
(\mathrm{m})\end{array}$ & $\begin{array}{c}\text { Power Transmitted } \\
(\mathrm{dBm})\end{array}$ & $\begin{array}{c}\text { Power Received } \\
(\mathrm{dBm})\end{array}$ & $\begin{array}{c}\text { Attenuation } \\
(\mathrm{dBm})\end{array}$ \\
\hline 1.950 & 52 & -93 & 145 \\
2.100 & 52 & -96 & 148 \\
2.150 & 52 & -97 & 149 \\
2.200 & 52 & -100 & 152 \\
2.250 & 52 & -102 & 154 \\
2.300 & 52 & -110 & 162 \\
2.400 & 52 & -114 & 166 \\
2.500 & 52 & -118 & 170 \\
2.650 & 52 & -120 & 172 \\
2.850 & 52 & -125 & 177 \\
\hline
\end{tabular}

Measurements and values for the Month of June.

Research Area: StarTimes Office, Olu-Obasanjo Road. Frequency of Transmission: 680MHz (UHF band).

Date: $17 / 6 / 2019$.

TABLE IV: READINGS AT THE RESEARCH AREA

\begin{tabular}{cccc}
\hline $\begin{array}{c}\text { Distance } \\
(\mathrm{m})\end{array}$ & $\begin{array}{c}\text { Power Transmitted } \\
(\mathrm{dBm})\end{array}$ & $\begin{array}{c}\text { Power Received } \\
(\mathrm{dBm})\end{array}$ & $\begin{array}{c}\text { Attenuation } \\
(\mathrm{dBm})\end{array}$ \\
\hline 2.100 & 52 & -95 & 147 \\
2.200 & 52 & -99 & 151 \\
2.250 & 52 & -101 & 153 \\
2.300 & 52 & -103 & 155 \\
2.400 & 52 & -106 & 158 \\
2.550 & 52 & -108 & 160 \\
2.600 & 52 & -110 & 162 \\
2.650 & 52 & -111 & 163 \\
2.750 & 52 & -126 & 178 \\
3.000 & 52 & -128 & 180 \\
\hline
\end{tabular}

Measurements and values for the Month of July. Research Area: StarTimes Office, Olu-Obasanjo Road. Frequency of Transmission: $680 \mathrm{MHz}$ (UHF band).

Date: $15 / 7 / 2019$.

TABLE V: READINGS AT THE RESEARCH AREA

\begin{tabular}{cccc}
\hline $\begin{array}{c}\text { Distance } \\
(\mathrm{m})\end{array}$ & $\begin{array}{c}\text { Power Transmitted } \\
(\mathrm{dBm})\end{array}$ & $\begin{array}{c}\text { Power Received } \\
(\mathrm{dBm})\end{array}$ & $\begin{array}{c}\text { Attenuation } \\
(\mathrm{dBm})\end{array}$ \\
\hline 0.9200 & 52 & -82 & 134 \\
0.9600 & 52 & -88 & 140 \\
0.9800 & 52 & -95 & 147 \\
1.110 & 52 & -97 & 149 \\
1.130 & 52 & -102 & 154 \\
1.200 & 52 & -104 & 156 \\
1.350 & 52 & -115 & 167 \\
1.560 & 52 & -121 & 173 \\
2.050 & 52 & -124 & 176 \\
2.550 & 52 & -125 & 177 \\
\hline
\end{tabular}

Measurements and values for the Month of August. Research Area: StarTimes Office, Olu-Obasanjo Road. Frequency of Transmission: $680 \mathrm{MHz}$ (UHF band).

Date: $19 / 8 / 2019$.

\section{TABLE VI: READINGS AT THE RESEARCH AREA}

\begin{tabular}{cccc}
\hline Distance $(\mathrm{m})$ & $\begin{array}{c}\text { Power } \\
\text { Transmitted } \\
(\mathrm{dBm})\end{array}$ & $\begin{array}{c}\text { Power Received } \\
(\mathrm{dBm})\end{array}$ & $\begin{array}{c}\text { Attenuation } \\
(\mathrm{dBm})\end{array}$ \\
\hline 1.875 & 52 & -86 & 138 \\
1.890 & 52 & -90 & 142 \\
1.895 & 52 & -93 & 145 \\
1.910 & 52 & -100 & 152 \\
1.920 & 52 & -104 & 156 \\
1.930 & 52 & -106 & 158 \\
1.960 & 52 & -108 & 160 \\
2.000 & 52 & -112 & 164 \\
2.115 & 52 & -119 & 171 \\
2.300 & 52 & -121 & 173 \\
\hline
\end{tabular}




\section{RESUlts AND Discussions}

In order to analyze the path loss (Attenuation) mathematically, two very important parameters was considered, the parameters are the pathloss exponent (n) and the Mean Square Error Value (MSE). The pathloss exponent represented as $\mathrm{n}$ shows the rate at which the signal decays as it propagates. The value of $n$ in free space without any obstruction is given as 2. However, in cases where obstruction exist, the pathloss exponent $\mathrm{n}$ will have a greater figure as high as 8 or above. And the path loss exponent is a function of carrier frequency and obstruction.

According to the log-normal shadowing model, the average path loss PL(d) for any transmitter to receiver spacing $d$ is:

$P_{L}(d B)=P L(d i)+10 n \log \left(\frac{d}{d_{o}}\right)+X \sigma$

Where:

$d_{o}$ represents the transmitter to receiver reference distance and has a typical value of $1 \mathrm{~km}$ in a macro cell system, $100 \mathrm{~m}$ in a micro cell system, $1 \mathrm{~m}$ in a pico cell systems [8] and $\mathrm{X} \sigma$ $=$ Zero Mean Gaussian Random Distributed Variable with a standard deviation of $\sigma$ in $\mathrm{dB}$.

In order to compute the expression for both the path loss exponent ( $\mathrm{n}$ ) and the MSE value, where the measured pathloss is $P_{\mathrm{Lm}}$ and the predicted value $\mathrm{P}_{\mathrm{LP}}$, we apply

$$
\begin{gathered}
E(n)=\sum_{i=1}^{k}\left(P_{L M}-P_{L P}\right)^{2} \\
n=\sum_{i=1}^{k}\left(\frac{P_{L M}-P_{L P}(d o)}{\sum 10 n \log \left(\frac{d}{d o}\right)}\right)
\end{gathered}
$$

TABLE VII: SHOWS THE VALUES OF THE MEASURED PATHLOSS

\begin{tabular}{cccc}
\multicolumn{4}{c}{ AND PREDICTED PATHLOSS FOR THE RESEARCH AREA. } \\
\hline Distance $(\mathrm{m})$ & $\begin{array}{c}\text { Power } \\
\text { Received } \\
(\mathrm{dBm})\end{array}$ & $\begin{array}{c}\text { Measured } \\
\text { Pathloss (dBm) }\end{array}$ & $\begin{array}{c}\text { Predicted } \\
\text { Pathloss }\end{array}$ \\
\hline 0.520 & -62 & 114 & 114 \\
0.600 & -63 & 115 & $114+0.62 \mathrm{n}$ \\
0.720 & -68 & 120 & $114+1.41 \mathrm{n}$ \\
0.800 & -68 & 120 & $114+1.87 \mathrm{n}$ \\
0.870 & -72 & 124 & $114+2.24 \mathrm{n}$ \\
0.950 & -73 & 125 & $114+2.62 \mathrm{n}$ \\
1.050 & -75 & 127 & $114+3.05 \mathrm{n}$ \\
1.110 & -77 & 129 & $114+3.29 \mathrm{n}$ \\
1.250 & -83 & 135 & $114+3.81 \mathrm{n}$ \\
1.400 & -89 & 141 & $114+4.30 \mathrm{n}$ \\
\hline
\end{tabular}

From the table above the value of total measured path loss $(\mathrm{dB})$ is equal to 1250 and that of the predicted path loss $(\mathrm{dB})$ is $1140+23.21 n$. to obtain the path loss exponent, we apply the equation:

$$
\sum(n)=\sum_{i=1}^{k}\left(P_{L M}-P_{L P}\right)^{2}
$$

Where $\mathrm{P}_{\mathrm{LM}}$ is 1250 and $\mathrm{P}_{\mathrm{LM}}$ is $1140+23.21 \mathrm{n}$

$$
\sum(n)=[1250-(1140+23.21 n)]^{2}
$$

$$
=12100-5106.2 \mathrm{n}+538.70 \mathrm{n}^{2}
$$

The value of $\mathrm{n}$, which is found to minimize the Mean Square Error (MSE), is deduced by equating the derivatives of equation to zero, and then solving for $n$.

$$
\frac{d E(n)}{d n}=0
$$

$$
S 106.2=2 n(538.70)
$$

$$
n=4.7
$$

This value reveals that Olu-Obasanjo is an sub urban area.

Randonness in pathloss ( $\left.\mathrm{P}_{\mathrm{LM}}(\mathrm{d})\right)$ with respect to any particular d value is usually recorded. It is represented as a distribute log centred around the mean distance defined by

$$
\mathrm{P}_{\text {measured }}(\mathrm{dB})=\mathrm{P}_{\text {predicted }}(\mathrm{do})+10 \mathrm{n} \log \left(\frac{d}{d o}\right)+X \sigma(21)
$$

$\mathrm{X} \sigma=$ Zero mean Gaussian distributed random variable with a standard deviation $\sigma$ in $\mathrm{dB}$.

$$
\begin{aligned}
& \sigma=\sqrt{\frac{\sum_{i=1}^{k}\left(P_{L M}-P_{L P}\right)^{2}}{N}} \\
& \left(\mathrm{P}_{\mathrm{LM}}-\mathrm{P}_{\mathrm{LP}}\right)^{2}=1210-5106 \mathrm{n}+538.70 \mathrm{n}^{2}=\sigma 13.2 \mathrm{Db} \\
& \mathrm{P}_{\mathrm{L}}(\mathrm{dB})=127.2+4.7 \log \mathrm{D}
\end{aligned}
$$

TABLE VIII: SHOWS THE MEASURED AND PREDICTED PATHLOSS VALUES IN THE RESEARCH AREA

\begin{tabular}{cccc}
\hline Distance $(\mathrm{m})$ & $\begin{array}{c}\text { Power } \\
\text { Received }(\mathrm{Pt}) \\
(\mathrm{dBm})\end{array}$ & $\begin{array}{c}\text { Measured } \\
\text { Pathloss (Pr) } \\
(\mathrm{dBm})\end{array}$ & $\begin{array}{c}\text { Predicted } \\
\text { Pathloss }\end{array}$ \\
\hline 0.9200 & -82 & 134 & 134 \\
0.9600 & -88 & 140 & $134+0.18 \mathrm{n}$ \\
0.9800 & -95 & 147 & $134+0.27 \mathrm{n}$ \\
1.110 & -97 & 149 & $134+0.81 \mathrm{n}$ \\
1.130 & -102 & 154 & $134-0.89 \mathrm{n}$ \\
1.200 & -104 & 156 & $134+1.15 \mathrm{n}$ \\
1.350 & -115 & 167 & $134+1.67 \mathrm{n}$ \\
1.560 & -121 & 173 & $134+2.29 \mathrm{n}$ \\
2.050 & -124 & 176 & $134+3.48 \mathrm{n}$ \\
2.550 & -125 & 177 & $134+4.43 \mathrm{n}$ \\
\hline
\end{tabular}

From the table above, the total measured pathloss $(\mathrm{dB})$ is equal to 1573 whereas the predicted pathloss $(\mathrm{dB})$ is $1340+$ $15.17 \mathrm{n}$.

Pathloss exponent is obtained by

$$
\begin{aligned}
& \sum(n)=\left[(1573-(1340+15.17 n)]^{2}\right. \\
& \partial(\mathrm{n})=0 \\
& 7069.22=2 \mathrm{n}(230.13) \\
& \mathrm{n}=15.4
\end{aligned}
$$




$$
\begin{aligned}
& \sigma=\sqrt{\sum_{i=i}^{k} \frac{\left(P_{L M}-P_{L P}\right)^{2}}{N}} \\
& \left(\mathrm{P}_{\mathrm{LM}}-\mathrm{P}_{\mathrm{LP}}\right)_{2}=54289-7069.22 \mathrm{n}+230.13 \mathrm{n}^{2}
\end{aligned}
$$

Where $\mathrm{n}=15.4, \mathrm{~N}=10$

$$
\sigma=0.64 \mathrm{~dB}=1 \mathrm{~dB}
$$

Therefore the resultant pathloss model while substituting the values $\mathrm{n}=15.4, \mathrm{P}_{\mathrm{L}}(\mathrm{dB})=134, \mathrm{X} \sigma=1 \mathrm{~dB}, \mathrm{P}_{\mathrm{L}}(\mathrm{dB})=135$ $+134 \log \mathrm{D})$

From the value of pathloss exponent (n) of 4.1 obtained, it reveals that the Olu-Obasanjo road is sub urban area. As the location changed as a result of the drive test, the value increased to 15.4 revealing the interference of tall buildings and other forms of obstructions.

\section{A. Presentation of Results}

The exponential decaying shape of the graph shows a loss in transmitted power as the distance between the transmitter and receiver increases and revealing an inverse relationship between the powers received $(\mathrm{dBm})$ and the distance $(\mathrm{km})$
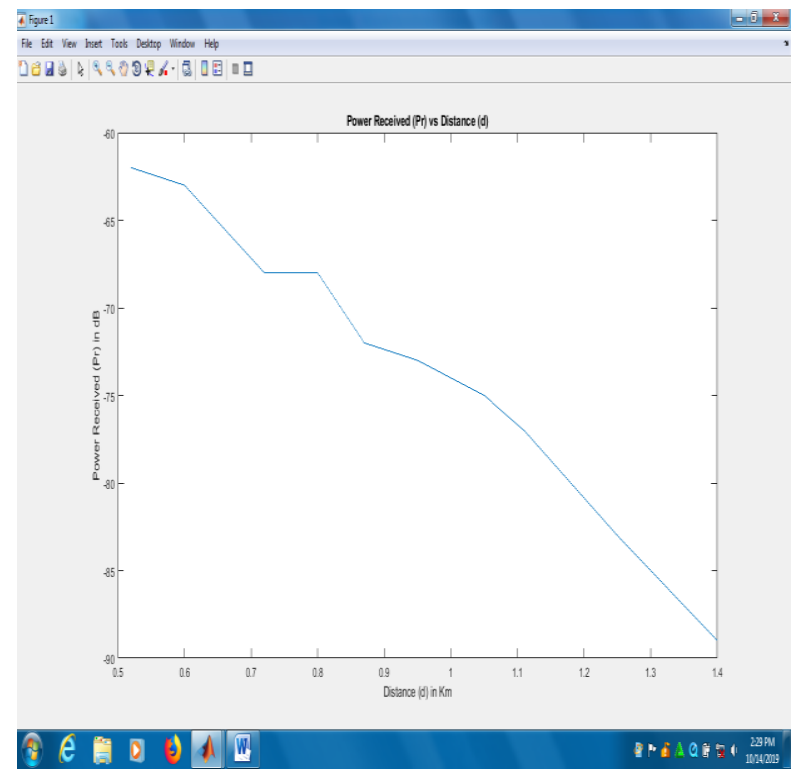

Fig.3. Plot of Power Received (Pr) against Distance (d) for the Month of April.

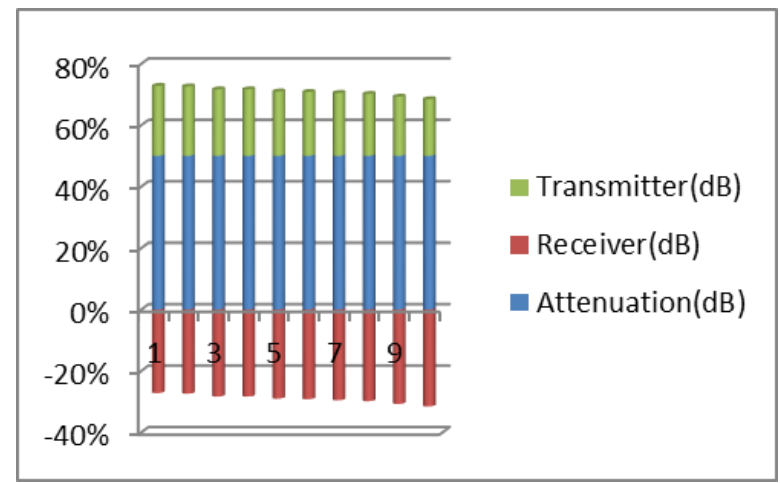

Fig 4. Analysis of Path loss in the Month of April.

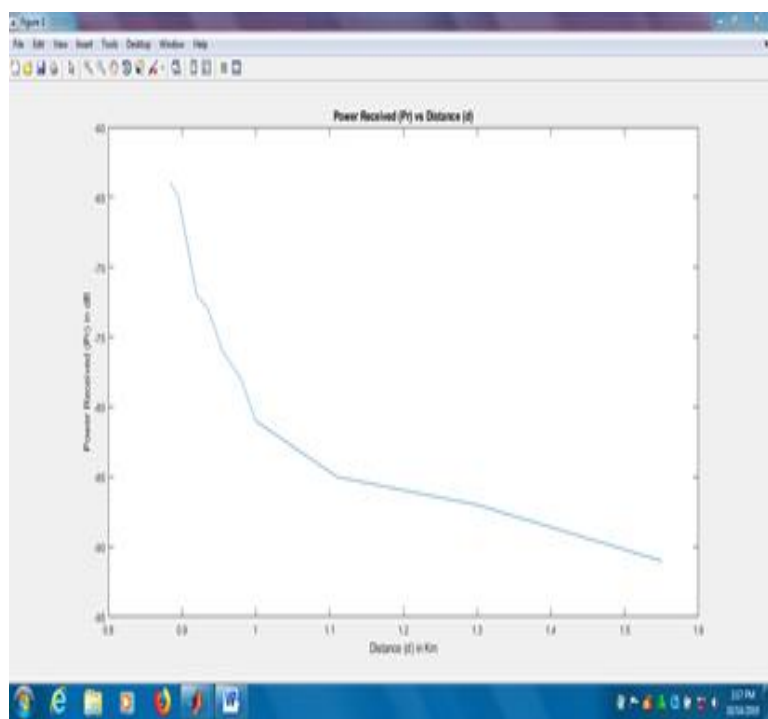

Fig.5 A Plot of Power Received (Pr) against Distance (d) for the Month of May.

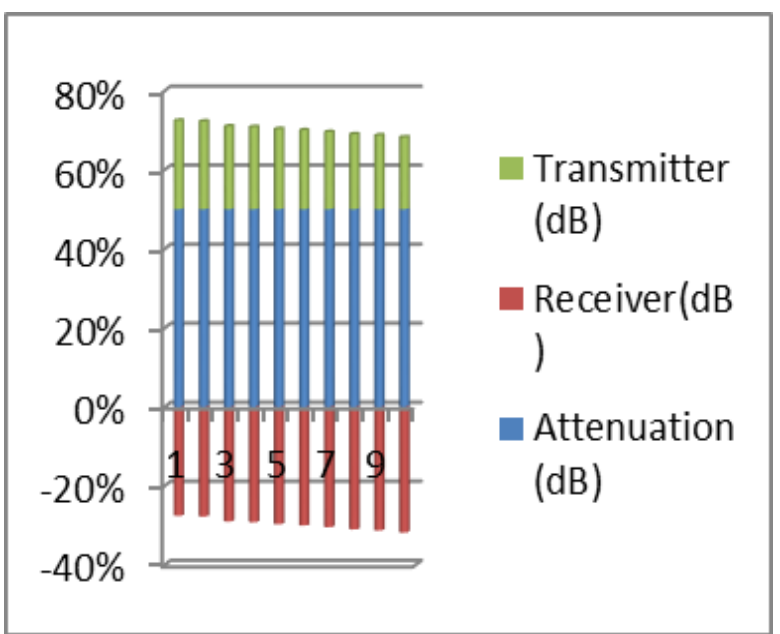

Fig. 6 Analysis of path loss in the Month of May.

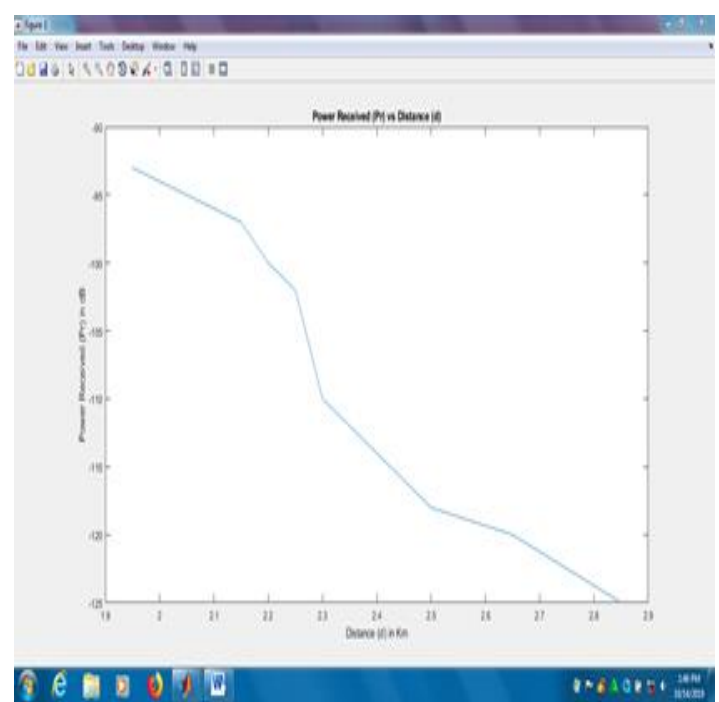

Fig.7. A Plot of Power Received (Pr) against Distance (d) for the Month of June. 


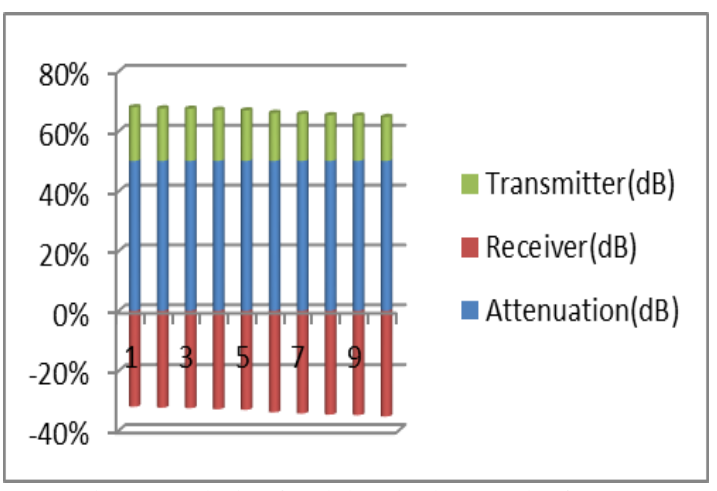

Fig. 8. Analysis of path loss in the Month of June.

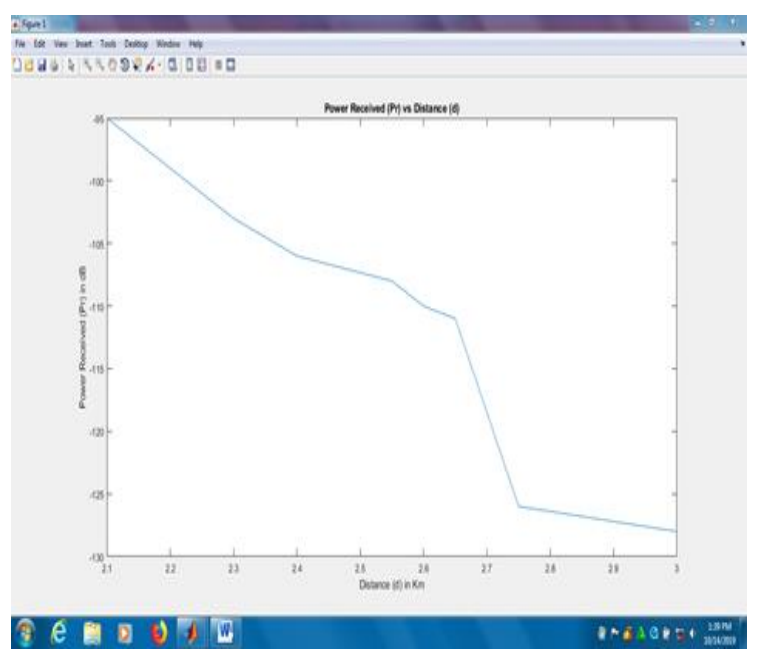

Fig 9. A Plot of Power Received (Pr) against Distance (d) for the Month of July.

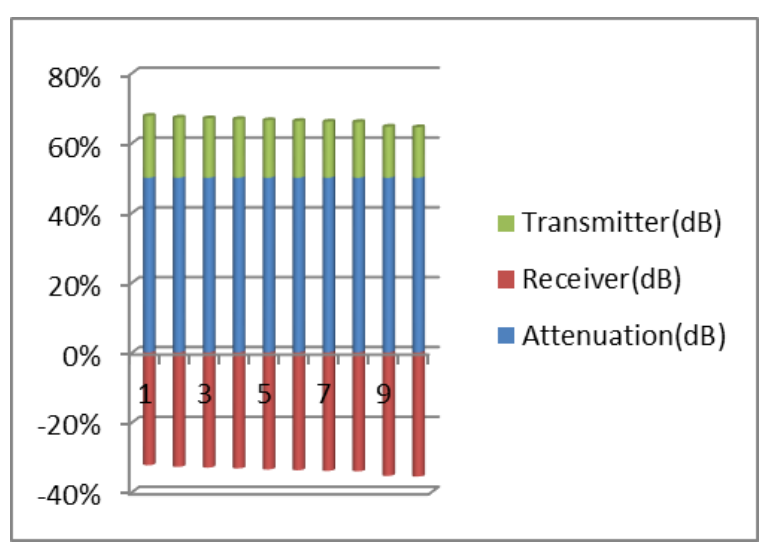

Fig,10. Analysis of path loss in the Month of July.

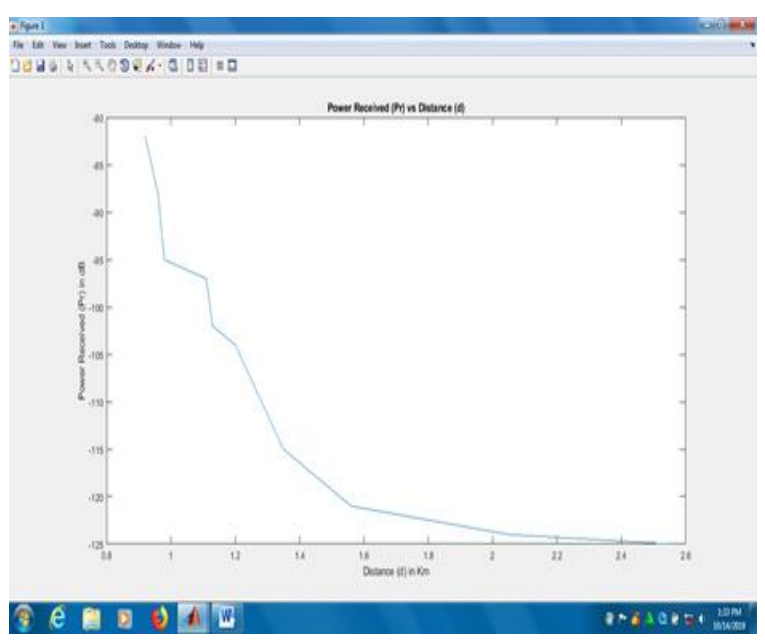

Fig.11. A Plot of Power Received (Pr) against Distance (d) for the Month of August.

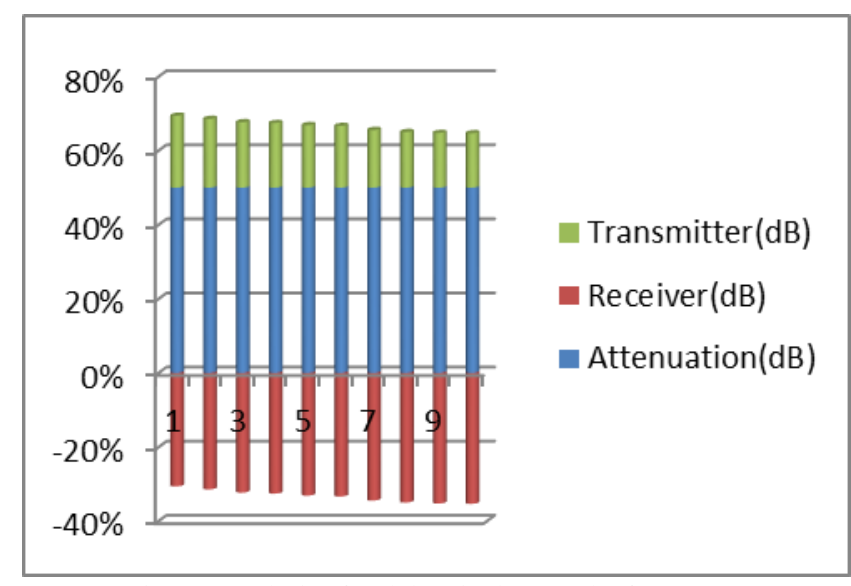

Fig. 12. Analysis of path loss in the Month of August.

\section{B. Discussion of Results}

The path loss exponent (n) of 4.7 reveals that the OluObasanjo road is an urban area. As the location changed, the path loss exponent (n) increased to 15.4, revealing the interference of tall buildings, and other forms of obstruction. The exponential shape of the graph shows a decaying signal along the distance axis with distance, expatiating that the inverse (1/D2) relationship between powers received $(\mathrm{dbm})$ and distance $(\mathrm{km})$. The Green, Blue and Red colour in the Bar Chart refers to the Transmitter, the Receiver and the Attenuation of signal strength level. From the observation, the transmitter efficiency is between $(60-80) \%$ and the receiver power level is between $(0-40) \%$, indicating low signal strength, while the Attenuation is between (-40-0)\%, revealing a great loss in the transmitted power on its arrival at the receiver. From the graphs, some months and days have different degree of signals received, indicating that meteorological factors such as rain, moist atmosphere etc., greatly influence the effect of Attenuation of TV signal from the research work.

\section{CONCLUSION}

This dissertation has been able to analyze the factors responsible for Digital Terrestrial Television Signal Attenuation. From the results arrived at, distance between the Transmitter and the Receiver (T-R) is a major cause of signal attenuation. When the receiver is outside the coverage area of the Transmitter, the signal may either cease or be very weak. Factors of precipitation, such as rain, moist air, and meteorological factors of the atmosphere greatly affect the broadcast of Digital Terrestrial Television (DTT).

After carrying out a comparative analysis of the different path loss models used in wireless communication, the empirical log normal path loss model and showing model were employed, owing to the fact that it revealed an inverse relationship between the signal strength and the distance. The greater the distance, the less the signal strength received. Therefore, in the design of transmission system, the right propagation model must be applied. Every environment and every season should adopt the right propagation model. 


\section{REFERENCES}

[1] M. O. Ajewole, A. Adediji and J. S. Ojo, (July, 2014). Precipitation Effect on the Coverage Areas of Terrestrial UHF Television Stations in Ondo State, Nigeria International Journal of Engineering and Technology vol. 4(9), pp. 524-535.

[2] M. Sititsamitpong and H. Mitomo, (March, 2013). An Analysis of factors Affecting the Adoption of Digital Terrestrial Television Services in Thailand, International Journal of Managing Public Sector Information and Communication Technologies (1JMPICT).

[3] P. Dhok and A. Dhanvijay, (August, 2015). A Review on Digital Video Broadcasting Terrestrial (DVB-T) Based OFDM System, International Journal of Engineering and Techniques. vol. 2(2), pp. 27-31.

[4] E. F. Gyanfi, Technical Challenges of Transition from Analog to Digital transmission. M.Sc Thesis, Dept. Telecommunication Engineering, Kwame Ukrumah Univ. of Science and Technology, Kumasi, Ghana, 2015.

[5] W. Ajibola "Signal Processing of Information for Digital Broadcast, case study: Nigeria and Kenya". A Thesis submitted to Central Ostrobothnia University of Applied Sciences for a Degree Programme in Information Technology, 2015.

[6] B.I Bakare and E, Akujobi (2018). A Critical Review of Digital Terrestrial Television Broadcasting in Nigeria. European Journal of Electrical and Computer Engineering (EJECE) 2 (7) 01-04 Available: htttps://doi.org/10.24018/ejece.2018.2.7.45.

[7] A. A. Nwankoro and K. C. Emerole (April, 2015). A case study of Propagation Path-Loss Models, American Journal of Engineering Research, Vol. 4, pp. 11.

[8] S. T. Rappaport, "Wireless Communications Principle and Practice", 2nd Ed. 2006, pp. 106-150.

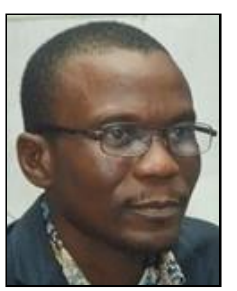

B. I. Bakare holds a Bachelor of Engineering (B.Eng.) Degree in Electrical Engineering; $\mathbf{2}^{\mathbf{1}}$ from Ondo State University, Ado Ekiti, ( Now University of Ado Ekiti, Ekiti State), Master of Engineering (M.Eng.) Degree in Electrical/Electronic Engineering from University of Port Harcourt,(UNIPORT), Nigeria and he is currently a $\mathrm{PhD}$ (Communication Engineering) Researcher of Nnamdi Azikiwe University (Unizik), Awka, Anambra State. He holds a Category One Electrical Wiring License. He is a COREN registered Engineer, a Corporate Member of Nigeria Society of Engineers (NSE), a member of International Association of Engineers (I A ENG) and an active member of Nigeria Institute of Electrical and Electronics Engineers (NIEEE). He is presently a lecturer in the Department of Electrical Engineering, Rivers State University, Port Harcourt., Nigeria. He is married with children, and can be reached on: bakare.bodunrin@ust.edu.ng

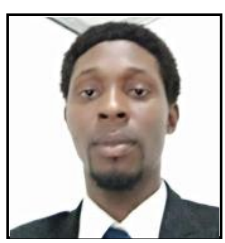

K. J. Biebuma holds a Bachelor of Engineering (B.Eng.) degree in Electrical/Electronic Engineering from University of Port Harcourt, (UNIPORT), Nigeria and he is currently an M.Tech (Communication Engineering Option) Researcher of Rivers State University, Nkpolu Oruworukwo, Port Harcourt, Rivers State.

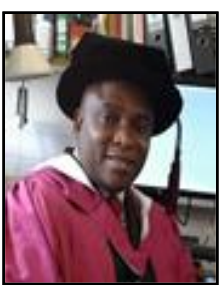

Sunny Orike received his B. Tech. in Computer Engineering from Rivers State University of Science and Technology (now Rivers State University); M.Sc. in Computing and M.Phil. in Computational Intelligence, both from Robert Gordon University, Aberdeen, United Kingdom; and $\mathrm{Ph} . \mathrm{D}$ in Artificial Intelligence from HeriotWatt University, Edinburgh, United Kingdom.

Dr. Orike is an active member of several professional bodies, including Council for the Regulation of Engineering in Nigeria, Nigeria Institution of Electrical Electronic Engineers and International Association of Engineers. He is a Senior Lecturer and Head, Department of Computer Engineering, Rivers State University, Port Harcourt, Nigeria.

Dr. Orike has published in several reputable journals, presented at both local and international conferences, and acts as a reviewer to several journals. He is a Facilitator with the National Open University of Nigeria, and External Assessor for Port Harcourt Polytechnic, Nigeria. He is married with children. 